\title{
Sclerostin: an emerging target for the treatment of cancer-induced bone disease
}

Michelle M. McDonald ${ }^{1,2}$, Jesus Delgado-Calle ${ }^{3,4,5}$

${ }^{1}$ The Garvan Institute of Medical Research, ${ }^{2}$ UNSW, Sydney, Australia, ${ }^{3}$ Division of Hematology/Oncology, Department of Medicine, Indiana University School of Medicine, ${ }^{4}$ Melvin and Bren Simon Cancer Center, ${ }^{5}$ Indiana Center for Musculoskeletal Health, Indianapolis, Indiana, USA.

\section{Corresponding author's information:}

Jesus Delgado-Calle, Ph.D.

Division of Hematology/Oncology, Department of Medicine, Indiana University School of Medicine

980 W. Walnut Street, Suite R3 C310, Indianapolis, IN 46202

Phone: 317 278-7705

Fax: 317-274-0396

Email: jdelgad@iupui.edu

Michelle M. McDonald ORCID \#: 0000-0002-3928-2506

Jesus Delgado-Calle ORCID \#: 0000-0002-2083-2774

This is the author's manuscript of the article published in final edited form as:

McDonald, M. M., \& Delgado-Calle, J. (2017). Sclerostin: an Emerging Target for the Treatment of Cancer-Induced Bone Disease. Current Osteoporosis Reports, 15(6), 532-541. https://doi.org/10.1007/s11914-017-0403-y 


\begin{abstract}
Purpose of review

This review provides a summary of the current knowledge on Sost/sclerostin in cancers targeting bone, discusses novel observations regarding its potential as a therapeutic approach to treat cancer-induced bone loss, and proposes future research needed to fully understand the potential of therapeutic approaches that modulate sclerostin function.
\end{abstract}

\title{
Recent findings
}

Accumulating evidence shows that sclerostin expression is dysregulated in a number of cancers that target bone. Further, new findings demonstrate that pharmacological inhibition of sclerostin in preclinical models of multiple myeloma results in a robust prevention of bone loss and preservation of bone strength, without apparent effects on tumor growth. These data raise the possibility of targeting sclerostin for the treatment of cancer patients with bone metastasis.

\section{Summary}

Sclerostin is emerging as a valuable target to prevent the bone destruction that accompanies the growth of cancer cells in bone. Further studies will focus on combining anti-sclerostin therapy with tumor targeted agents to achieve both beneficial skeletal outcomes and inhibition of tumor progression. 
Keywords (4-6 key words): Sost/sclerostin, cancer, bone, myeloma, osteoblasts, osteoclasts 


\section{Introduction}

Bone is a frequent and preferred site for cancer metastases and cancer involvement. Up to $70 \%$ of patients with advanced breast or prostate cancer present with bone metastasis, and over 90\% of patients with multiple myeloma develop osteolytic bone lesions. Upon dissociation from the primary tumor, metastatic cells populate the highly vascularized environment of the bone marrow with a strong affinity. Once bone is colonized, tumor cells in bone may start to grow immediately or survive in a dormant state until activated to initiate tumor formation [1]. The exponential growth of tumor cells in bone disrupts normal bone remodeling driving local bone destruction, induces

severe pain, and increases fracture rates dramatically, thereby increasing mortality and reducing the likelihood for disease remission [2].

Current research in bone metastasis aims to develop a greater understanding of the interactions between tumor cells and the cells of the bone marrow environment. The bone microenvironment controls tumor cell dormancy and regulates tumor cell activation through osteoclastic bone resorption during both disease initiation and recurrence [3-6]. In addition, interaction of cancer cells with different cell types in the bone microenvironment induces the secretion of multiple cytokines that stimulate bone resorption and fuel tumor growth [7-9]. Although less well explored, alterations in bone formation act in concert with altered bone resorption in response to the presence of cancer cells in bone, particularly in multiple myeloma [10-12]. Moreover, interactions with stromal cells promote growth, invasion, and metastasis [13]. Hence, we have compelling evidence that interactions between tumor cells and osteoblasts, osteoclasts, and stromal cells present in the bone marrow microenvironment influence tumor behavior and contribute to the development of osteolytic lesions [3;14-16].

Recently, attention has turned to the role of osteocytes in the tumor microenvironment. Osteocytes are the most abundant and long-lived cells in bone and are master regulators of bone remodeling [17-19]. Accumulating data supports that osteocyte function and life span are altered in bones colonized by cancer cells and that osteocytes favor tumor progression and bone destruction [17;20]. Further, the expression of the osteocyte-derived factor sclerostin, a potent inhibitor of bone formation, is increased in a number of cancers that target the skeleton [21-26], suggesting that this protein could play a part in the inhibition of bone formation that accompanies the growth of cancer cells in bone. In this review, we provide a summary of the role of sclerostin in cancer-induced bone disease 
and the potential of using neutralizing antibodies against sclerostin as novel therapeutic approach to improve outcomes, quality of life, and survival in cancer patients.

\section{Sost/sclerostin: a negative regulator of bone mass and much more}

Sclerostin, encoded by the gene Sost, was first identified through genetic linkage analyses in sclerosteosis and van Buchem's disease patients [27;28]. Mutations in the Sost gene observed in these patients result in absence of sclerostin expression or secretion, leading to high bone mass due to exaggerated bone formation [29;30]. Numerous studies followed this discovery, unravelling the numerous mechanisms of action of Sost/sclerostin in regulating bone mass (Fig. 1) [31]. In rodents, genetic deletion of Sost/sclerostin results in a progressive and generalized increase in bone mass due to increases in the number and bone-forming activity of osteoblasts [32]. In contrast, sclerostin overexpression reduces bone formation and bone mass in mice [33-35]. Mechanistic studies demonstrated that sclerostin acts as an extracellular inhibitor of canonical Wnt signaling. Assisted by LDL receptor related protein (LRP) 4, sclerostin binds to LRP5 and LRP6, and antagonizes downstream Wnt/ $\beta$-catenin signaling [36;37], a pathway that stimulates bone formation and negatively regulates bone resorption to enable bone acquisition and maintain bone homeostasis. These findings led to the hypothesis that inhibition of sclerostin might restore bone mass and strength in the osteoporotic skeleton. Amgen (romosozumab), Eli Lilly (blosozumab), and Novartis (BPS804) guided the development of neutralizing antibodies to therapeutically target sclerostin, which resulted in a vast array of animal and human clinical studies demonstrating the ability of anti-sclerostin antibodies to stimulate bone formation and increase bone mass and strength (discussed in section 4).

In the last years, there has been an expansion of our knowledge of the actions of sclerostin in both skeletal and non-skeletal tissues. Although osteoblasts are the main target cells for sclerostin in bone, it has become apparent that anti-sclerostin antibodies also decrease bone resorption (Fig. 1), suggesting that sclerostin also regulates the differentiation and function of osteoclasts [38]. In this line, sclerostin-mediated inhibition of Wnt/ $\beta$-catenin signaling leads to a reduction in osteoprotegerin (Opg) expression in osteoblasts and osteocytes, a soluble decoy for the master regulator of osteoclastogensis termed receptor activator of nuclear factor kappa-B ligand (Rankl), with consequent increases in osteoclastic resorption [39-41]. Overexpression of Sost/sclerostin also increases the expression of Rankl in bone [35;42]. Further, constitutive activation of Wnt/ $\beta$-catenin signaling in osteocytes also

increases Rankl expression [42], an effect driven by sclerostin production [42]. Moreover, addition of recombinant 
sclerostin to cultures of MLO-Y4 osteocytic cells is sufficient to upregulate Rankl and enhance osteocyte-induced osteoclast formation in vitro [43]. Recent findings suggest that sclerostin could also play a part in the regulation of adipocyte differentiation and/or fat production (Fig. 1). Sclerostin induces adipogenesis through inhibition of Wnt signaling in pre-adipocytes in vitro, and genetic and pharmacological inhibition of sclerostin in vivo decreases bone marrow adipose tissue formation [44-48]. Further, increased sclerostin in the circulation results in a progressive loss of white adipose tissue in gonadal and inguinal stores, an effect associated with decreased white adipocyte markers, increased beige adipocytes, and reduced canonical Wnt/ $\beta$-catenin signaling in these fat depots [49]. Finally, neutralization of sclerostin stimulates the conversion of bone lining cells into active osteoblasts [50], supporting the notion that sclerostin can regulate the pool of quiescent bone lining cells in bone (Fig. 1). Altogether, these findings indicate that sclerostin can target different cells in the bone marrow microenvironment. In addition, similar to other factors secreted by osteocytes/osteoblasts, these results suggest that sclerostin has an endocrine metabolic action complementary to its function in bone. Further investigation is warranted to determine the importance of circulating sclerostin levels and their impact in non-skeletal tissues.

Despite our increased knowledge in Sost/sclerostin biology, the specific mechanisms by which this gene is regulated remain as an outstanding unresolved issue. Sclerostin expression is mainly detected in osteocytes, osteocytic lacunae, and along osteocytic canaliculi, indicating that Sost/sclerostin is expressed by mature osteocytes, but not by early osteocytes or osteoblasts [51]. It is important to note that recent evidence suggests that other cells in the bone marrow microenvironment might also express Sost/sclerostin, particularly during development or under pathological conditions [26;52-63]. Yet, whether sclerostin produced by other cells than osteocytes contributes to the skeletal effects attributed to this protein is unclear. The regulation of Sost/sclerostin expression is complex and requires coordination of multiple mechanisms to control sclerostin production in a time and cell-context manner. The first regulatory sequence in the Sost gene was identified in van Buchem patients, which present a homozygous deletion of a 52-kb noncoding located $\sim 35 \mathrm{~kb}$ downstream of the Sost transcription start site [34;64]. This sequence contains an enhancer element essential for Sost expression, the evolutionarily conserved region 5 (ECR5). The ECR5 has response elements for the myocyte enhancer factor-2 (Mef2c), a transcription factor that upon binding to ECR5 stimulates Sost mRNA expression [65;66]. Also, epigenetic modifications in the Sost proximal promoter ( 1.4Kb upstream the SOST gene), in particular DNA methylation, are responsible for the repression of Sost/Sclerostin expression in osteoblastic cells, and elimination of DNA methyl marks during osteoblast-osteocyte 
transition enables the expression of this gene in osteocytes [67;68]. Further, several hormonal stimuli and transcription factors that bind to regulatory regions of the Sost gene and control its transcription have been identified, including parathyroid hormone [65;69-71], transforming growth factor beta and activin-A [72], bone morphogenetic proteins [72-74], tumor necrosis factor alpha and Tnf-related weak inducer of apoptosis [75], and more recently osteoclast-derived leukemia inhibitory factor [76]. Future research efforts should focus on understanding the interplay between the different epigenetic marks and transcription factors, and identifying the specific regulatory mechanisms that lead to the dysregulation of sclerostin expression in bone pathologies, including those caused by cancer.

\section{Sost/sclerostin in other bone tumors and cancers that metastasize to bone}

The contribution of osteocytes and their derived factors to cancer-induced bone disease is an emerging area of research [77]. Autophagic/apoptotic osteocytes are increased in bone areas infiltrated with myeloma cells [78-80], and reciprocal interactions between myeloma cells and osteocytes alter osteocyte viability and stimulate proliferation in myeloma cells. Also, recent data show that osteocytes can communicate with sensory nerves and contribute to myeloma-induced bone pain [81], one of the most common symptoms of multiple myeloma. In response to increased intraosseous pressure resulting from the growth of prostate cancer cells in the bone marrow, osteocytes produce chemokine (C-C motif) ligand 5, which in turn stimulates the synthesis of matrix metalloproteinases to favor the growth and invasion of prostate cancer cells into bone [20]. Further, recent findings suggest that osteocytes, in addition to osteoblasts, may act as a cell of origin for osteosarcoma [82]. Together, these data support a role for osteocytes in providing a microenvironment that is conducive to tumor growth and the subsequent skeletal destruction and bone pain.

Key to osteocyte regulation of bone response to cancer cell colonization is the osteocyte-derived protein sclerostin. The expression of sclerostin has been assessed both at bone tissue level and systemically in the circulation in a number of cancers that target bone [83], with some conflicting data. In a small cohort of patients, circulating sclerostin levels were higher in postmenopausal women with endocrine-responsive breast cancer compared to those in the premenopausal group, and serum sclerostin increased after treatment with aromatase inhibitors [21;22]. Further, MDA-MB-231 breast cancer cells secrete sclerostin to inhibit osteoblast differentiation through a mechanism dependent on both Runx2 and $\operatorname{CBF} \beta$ [84]. Circulating sclerostin levels are also significantly 
increased in patients with prostate cancer, particularly in those receiving androgen deprivation therapy [23;24]. Sclerostin levels remained unaltered however in renal cell carcinoma patients with osteolytic metastases or patients with indolent systemic mastocytosis [85;86]. It is important to note that sclerostin expression in bone does not always correlate with sclerostin levels in the circulation [87;88]. Indeed, in contrast to clinical studies, preclinical experiments in rodents show that sclerostin has the potential to inhibit prostate cancer invasion and to reduce the incidence of metastases and bone destruction [89;90]. Thus, evaluation of sclerostin at the tissue level is required to determine the levels of this protein in bone and properly assess its potential contribution to the effects of cancer in bone. Nevertheless, these results suggest that the regulation and function of sclerostin may differ among cancers that target bone. Therefore, combinations of clinical measurements of sclerostin with data from animal models are essential to predict the clinical outcome of targeting sclerostin in different bone destructive cancers.

\section{Sost/sclerostin dysregulation in multiple myeloma}

Elevated sclerostin expression has been implicated in the pathogenesis of bone loss in patients with myeloma, with a number of clinical investigations showing increased serum sclerostin levels in myeloma patient samples compared to healthy subjects or MGUS patients [25;26]. Increased levels of Sost mRNA were found in plasma cells isolated from small cohorts of patients with myeloma [62;63;91], suggesting that myeloma cells are the main source of sclerostin. However, in a more recent study including over 630 myeloma patients, bone marrow plasma cell Sost mRNA was not different to healthy controls, nor was it detected in 56 human or murine myeloma cells lines [92], suggesting elevated serum levels of sclerostin were driven by another source. Indeed when sclerostin plasma concentrations were compared with Sost mRNA and sclerostin protein expression in bone marrow mesenchymal stromal cells and osteocytes, a strong correlation was demonstrated [26], indicating that bone cells are mainly responsible for the increased serum sclerostin levels detected in patients with myeloma. Supporting this notion, in vitro experiments show that physical interactions with myeloma cells increase Sost mRNA expression in osteocytes, and the number of osteocytes expressing sclerostin doubled in bones bearing myeloma cells versus healthy controls [79;92;93]. These results led many to hypothesize that elevated sclerostin levels in the bone/bone marrow microenvironment are causal of the suppressed bone formation induced by myeloma, and positioned sclerostin as a bone specific targetable candidate to promote bone formation and overcome bone loss in patients with myeloma. 


\section{Sost/Sclerostin as a therapeutic tool to prevent cancer induced bone loss}

Due to the devastating consequences of tumor cell metastasis and myeloma cell expansion in bone, extensive pre-clinical and clinical research has led to the clinical use of bone targeted therapies, such as the antiresorptive agents bisphosphonates and denosumab, to prevent bone destruction [94]. Besides stopping tumorinduced skeletal destruction, anti-resorptive therapies can also maintain tumor cells in a dormant state in bone, thus preventing their re-activation and subsequent disease recurrence [3]. Thus, anti-resorptives are considered the mainstay therapy for cancer patients with bone involvement. However, although anti-resorptive therapy is effective at preventing further bone loss, it cannot rebuild lost bone, and therefore fractures still occur in patients with myeloma and metastatic bone disease, even during remission. Thus, anabolic therapies that increase osteoblast activity and stimulate new bone formation are required to help restore bone structure and strength in cancer patients.

Sclerostin is now recognized as a target for the treatment of osteoporotic bone loss. Neutralizing antibodies to sclerostin have shown beneficial outcomes for bone mass and structure in preclinical studies in rodents, and have shown potent skeletal anabolic effects, with increases in bone strength and fracture risk reduction in phase II and III clinical trials for the management of osteoporosis [95-98]. Mechanistically, anti-sclerostin therapy uncouples bone formation from bone resorption, by stimulating osteoblast function while decreasing osteoclast function. These findings have attracted recent attention in the field of cancer, and in particular multiple myeloma [26;92;93], as a potential new avenue for rebuilding lost bone and preventing fractures in patients with bone destructive cancers.

Administration of anti-sclerostin antibodies increased bone volume in immunocompromised mice bearing MM1.S human xenograft cells [26]. Although bone loss compared to naïve control mice in response to MM1.S cells was not demonstrated in this study, anti-sclerostin antibodies increased cancellous bone volume and trabecular thickness in the vertebrae. The circulating levels of the bone formation marker P1NP were elevated by antisclerostin treatment, suggesting that stimulation of bone formation was responsible for the increased bone volume. More recently, both genetic deletion of Sost and pharmacologic inhibition with anti-sclerostin antibodies showed significant protection from myeloma-induced bone loss [92;93]. Immunocompetent mice bearing 5TGM1 or 5T2MM cells, and immunocompromised mice bearing human MM1.S cells showed significant trabecular bone loss

compared to naïve controls mice. Anti-sclerostin treatment prevented this bone loss, normalizing bone volume to naïve control levels, through increasing bone formation without altering bone resorption parameters [92]. Further, 
the development of osteolytic lesions, characteristic of the 5T2MM model, was also prevented with anti-sclerostin treatment, possibly via correcting the myeloma-induced dysregulation of coupling between bone resorption and formation. Importantly, anti-sclerostin-driven protection from bone loss also prevented the decrease in bone strength in mice bearing myeloma, suggesting that anti-sclerostin treatment may prevent myeloma-induced fractures. Noteworthy, anti-sclerostin treatment provided additive protection from 5TGM1-induced bone loss and compromised bone strength when combined with the anti-resorptive agent zoledronic acid [92]. Immunocompromised mice carrying a homozygous deletion of Sost were also protected from bone loss and the development of osteolytic lesions induced by human JJN3 myeloma cells through preservation of bone formation and a modest inhibition of bone resorption [93]. Remarkably, in the same study, administration of anti-sclerostin to mice with established/active myeloma disease, protected from trabecular bone loss and osteolytic lesions and demonstrated that anti-sclerostin stimulates new bone formation and reduces osteoclast numbers in areas colonized by myeloma cells. In concert, these results demonstrate that anti-sclerostin protects from myeloma-induced bone loss by primarily stimulating bone anabolism, with modest or undetectable effects on resorption, and support that combined therapeutic approaches targeting both bone suppression of anabolism and increased catabolism may provide optimal outcomes for myeloma-induced bone disease (Fig. 2).

Before clinical applications of anti-sclerostin antibody treatment can be considered in myeloma however, consideration must be given to the possible impact of stimulating Wnt signaling on tumor growth. Inhibiting a soluble Wnt antagonist may increase local Wnt signaling and promote tumor growth [99]. Whilst Wnt signaling stimulation of myeloma cell proliferation has been demonstrated in vitro [100], anti-sclerostin antibody treatment had no effect on skeletal and extra-skeletal myeloma burden across all models described above [26;92;93]. Also, anti-sclerostin did not alter the anti-myeloma activity of the proteasome inhibitor carfilzomib in vivo [26] or impact myeloma cell proliferation in vitro, either in the presence or absence of chemotherapeutic agents [92;93]. These findings suggest that sclerostin does not regulate pathways that control tumor growth, and open the possibility of combining anti-sclerostin therapy with chemotherapeutic drugs to achieve both beneficial skeletal outcomes and inhibition of tumor progression.

It is important to mention that sclerostin is not the only Wnt inhibitor elevated in patients with myeloma or bone metastasis. Suppression of osteoblast differentiation through TGF- $\beta$ signaling and Dkk-1 has also been 
implicated in bone lesions caused by breast cancer bone metastases [101-103]. Also, Dkk1 and SFRP3 mRNA expression was markedly elevated in bone marrow biopsies of 65 patients with myeloma with either absent or overt lytic bone disease [104]. In preclinical models, anti-Dkk1 successfully prevented myeloma-induced bone disease and had variable effects on tumor burden leading to early clinical trials [105-107]. These agents have not however succeeded to reach the clinic, possibly due to an inadequate bone anabolic capacity of the agents or the heterogeneous response of patients [92]. In a recent study, a bispecific antibody inhibiting both sclerostin and Dkk-1 was generated. Dual inhibition of sclerostin and Dkk-1 resulted in greater increases in bone formation and showed superior bone repair activity when compared to inhibition of each of the Wnt antagonists alone in animal models of osteoporosis [108]. Further investigation is needed to determine whether dual inhibition of Dkk-1 and sclerostin is also anabolic in bones colonized by cancer cells, has effects on tumor growth, and prevents fractures to a degree that exceeds that achieved with Wnt antagonist inhibitor monotherapy.

\section{Conclusions and future directions}

The discovery of sclerostin and its impact on the skeleton opened a new area in bone therapeutics. Recent results show that sclerostin production is elevated in bones colonized by cancer cells, raising the possibility of targeting sclerostin for the treatment of bone-destructive cancers. Recent animal studies demonstrate that pharmacological inhibition of sclerostin prevents bone loss and stimulates new bone formation in preclinical models of multiple myeloma. Anti-sclerostin antibodies also robustly enhance normal and compromised fracture repair and importantly increase BMP-driven repair of critical size defects [108-114]. Consistent with the anti-fracture properties of anti-sclerostin [96], pharmacological inhibition of sclerostin, either alone or in combination with zolendronic acid, prevents the decline in resistance to fracture in bones bearing myeloma and, in some instances, increased strength above naïve controls [92]. These findings support that anti-sclerostin has the potential to not only prevent bone loss and fractures, but rebuild lost bone and heal osteolytic lesions. Further investigations are required to ascertain whether anti-sclerostin could in fact repair lytic lesions; however, this is an exciting opportunity to dramatically improve outcomes in patients with established disease or those in remission. Future studies should also aim to identify the exact source of sclerostin and the mechanism(s) underlying its aberrant production in the setting of bone cancers. Also, the ability of anti-sclerostin antibodies to promote bone formation in other cancers that target bone warrants further investigation. The recent findings showing that adipocytes appear to affect different aspects of 
tumor cell biology [16;115-118], together with the new evidence that anti-sclerostin therapy decreases the number of adipocytes in the marrow [48], raise the possibility that sclerostin could play a part in the increased marrow adiposity observed in myeloma and others cancers in bone, and therefore demand further investigation. Finally, although preliminary, the new evidence showing that anti-sclerostin therapy does not alter tumor growth or the antitumor activity of chemotherapeutic drugs provides new avenues to simultaneously improve bone disease and decrease tumor burden in patients with cancer in bone. In conclusion, the current in vitro and in vivo data support the therapeutic targeting of sclerostin to prevent bone loss, stimulate new bone formation, and reduce the risk of fractures in patients with cancer in bone. These results may lead to the clinical investigation of the effects of antisclerostin therapy in cancer-induced bone disease. 


\section{Acknowledgements}

M.M.M is supported The Kay Stubbs Cancer Research Grant, Cancer Council NSW. J.D.C. work was supported by the International Bone and Mineral Society Gideon and Sevgi Rodan Fellowship, the American Society of Hematology Scholar Award, and the International Myeloma Foundation Brian D. Novis Junior Research Grant. 


\section{Compliance with Ethical Standards}

- Conflict of interest: Authors declare that have no conflict of interest.

- Animal and Human Studies: This article includes studies with mice performed by the author. All applicable international, national, and/or institutional guidelines for the care and use of animals were followed. All procedures performed in studies involving human participants were in accordance with the ethical standards of the institutional and/or national research committee and with the 1964 Helsinki declaration and its later amendments or comparable ethical standards. This article does not include any studies with humans performed by the authors. 


\section{Figure captions}

Fig. 1 Mechanisms of action of Sost/sclerostin in bone. Upon binding to LRP4, 5 and 6, sclerostin inhibits Wnt/ßcatenin signaling in mesenchymal stem cells and mature osteoblasts to decrease their proliferation and differentiation and bone forming activity, respectively. Recent findings show that inhibition of Wnt signaling in preadipocytes by sclerostin induces adipogenesis and increases bone marrow adipose tissue formation. Further, inhibition of Wnt/ßcatenin signaling in osteoblastic cells increases the Rankl/Opg ratio to favor osteoclast differentiation and bone resorption. Thus, neutralization of sclerostin has the potential to stimulate osteoblast differentiation and bone formation, reduce bone resorption, and decrease adipogenesis.

Fig. 2 Actions of Sost/sclerostin in multiple myeloma-induced bone disease. Sclerostin expression is elevated in bone colonized by cancer cells. Based primarily on research done in myeloma, the increase in sclerostin expression favors bone loss and osteolysis by reducing osteoblast numbers and their bone-forming activity and increasing osteoclast differentiation and bone resorption. In addition, it is possible that sclerostin also stimulates the differentiation of mesenchymal precursors towards the adipogenic lineage. Pharmacologic inhibition of sclerostin stimulates new bone formation and modestly reduces bone resorption, thus preventing the bone loss and restoring bone strength. The effects of anti-sclerostin in bone marrow adiposity in bones bearing cancer cells require further investigation. 


\section{References}

•of importance

••of high importance

1. Townson JL, Chambers AF. Dormancy of solitary metastatic cells. Cell Cycle 2006; 5:1744-1750.

2. Coleman RE. Clinical features of metastatic bone disease and risk of skeletal morbidity. Clin.Cancer Res. 2006; 12:6243s-6249s.

3. Croucher PI, McDonald MM, Martin TJ. Bone metastasis: the importance of the neighbourhood. Nat.Rev.Cancer 2016; 16:373-386.

4. Lawson MA, McDonald MM, Kovacic N, Hua KW, Terry RL, Down J, Kaplan W, Paton-Hough J, Fellows C, Pettitt JA, Neil DT, Van VE, Baldock PA, Rogers MJ, Eaton CL, Vanderkerken K, Pettit AR, Quinn JM, Zannettino AC, Phan TG, Croucher PI. Osteoclasts control reactivation of dormant myeloma cells by remodelling the endosteal niche. Nat.Commun. 2015; 6:8983.

5. Wang N, Docherty F, Brown HK, Reeves K, Fowles A, Lawson M, Ottewell PD, Holen I, Croucher PI, Eaton CL. Mitotic quiescence, but not unique "stemness," marks the phenotype of bone metastasisinitiating cells in prostate cancer. FASEB J. 2015; 29:3141-3150.

6. Wang N, Reeves KJ, Brown HK, Fowles AC, Docherty FE, Ottewell PD, Croucher PI, Holen I, Eaton CL. The frequency of osteolytic bone metastasis is determined by conditions of the soil, not the number of seeds; evidence from in vivo models of breast and prostate cancer. J.Exp.Clin.Cancer Res. 2015; 34:124.

7. Aggarwal R, Ghobrial IM, Roodman GD. Chemokines in multiple myeloma. Exp.Hematol. 2006; 34:12891295.

8. Roodman GD. Role of the bone marrow microenvironment in multiple myeloma. J Bone Miner.Res. 2002; 17:1921-1925.

9. Guise TA, Kozlow WM, Heras-Herzig A, Padalecki SS, Yin JJ, Chirgwin JM. Molecular mechanisms of breast cancer metastases to bone. Clin.Breast Cancer 2005; 5 Suppl:S46-S53.

10. Giuliani N, Rizzoli V, Roodman GD. Multiple myeloma bone disease: Pathophysiology of osteoblast inhibition. Blood 2006; 108:3992-3996.

11. Fairfield H, Falank C, Avery L, Reagan MR. Multiple myeloma in the marrow: pathogenesis and treatments. Ann.N.Y.Acad.Sci. 2016; 1364:32-51.

12. Roodman GD. Pathogenesis of myeloma bone disease. Leukemia 2009; 23:435-441.

13. Quail DF, Joyce JA. Microenvironmental regulation of tumor progression and metastasis. Nat.Med. 2013; 19:1423-1437.

14. Sterling JA, Edwards JR, Martin TJ, Mundy GR. Advances in the biology of bone metastasis: how the skeleton affects tumor behavior. Bone 2011; 48:6-15.

15. Olechnowicz SW, Edwards CM. Contributions of the host microenvironment to cancer-induced bone disease. Cancer Res. 2014; 74:1625-1631.

16. McDonald MM, Fairfield H, Falank C, Reagan MR. Adipose, Bone, and Myeloma: Contributions from the Microenvironment. Calcif.Tissue Int. 2017; 100:433-448. 
17. Delgado-Calle J, Bellido T. Osteocytes and Skeletal Pathophysiology. Curr.Mol.Biol.Rep. 2015; 1:157167.

18. Bellido T. Osteocyte-Driven Bone Remodeling. Calcif.Tissue Int. 2013; 94:25-34.

19. Delgado-Calle J, Bellido T, Roodman GD. Role of osteocytes in multiple myeloma bone disease. Curr.Opin.Support.Palliat.Care 2014; 8:407-413.

20. Sottnik JL, Dai J, Zhang H, Campbell B, Keller ET. Tumor-induced pressure in the bone microenvironment causes osteocytes to promote the growth of prostate cancer bone metastases. Cancer Res. 2015; 75:21512158.

21. Kim W, Chung Y, Kim SH, Park S, Bae JH, Kim G, Lee SJ, Kim JE, Park BW, Lim SK, Rhee Y. Increased sclerostin levels after further ablation of remnant estrogen by aromatase inhibitors. Endocrinol.Metab (Seoul.) 2015; 30:58-64.

22. Kyvernitakis I, Rachner TD, Urbschat A, Hars O, Hofbauer LC, Hadji P. Effect of aromatase inhibition on serum levels of sclerostin and dickkopf-1, bone turnover markers and bone mineral density in women with breast cancer. J.Cancer Res.Clin.Oncol. 2014; 140:1671-1680.

23. Garcia-Fontana B, Morales-Santana S, Varsavsky M, Garcia-Martin A, Garcia-Salcedo JA, Reyes-Garcia $\mathrm{R}$, Munoz-Torres M. Sclerostin serum levels in prostate cancer patients and their relationship with sex steroids. Osteoporos.Int. 2014; 25:645-651.

24. Yavropoulou MP, van Lierop AH, Hamdy NA, Rizzoli R, Papapoulos SE. Serum sclerostin levels in Paget's disease and prostate cancer with bone metastases with a wide range of bone turnover. Bone 2012; 51:153-157.

25. Terpos E, Christoulas D, Katodritou E, Bratengeier C, Gkotzamanidou M, Michalis E, Delimpasi S, Pouli A, Meletis J, Kastritis E, Zervas K, Dimopoulos MA. Elevated circulating sclerostin correlates with advanced disease features and abnormal bone remodeling in symptomatic myeloma: reduction postbortezomib monotherapy. Int.J.Cancer 2012; 131:1466-1471.

26. •Eda H, Santo L, Wein MN, Hu DZ, Cirstea DD, Nemani N, Tai YT, Raines SE, Kuhstoss SA, Munshi NC, Kronenberg HM, Raje NS. Regulation of Sclerostin Expression in Multiple Myeloma by Dkk-1; A Potential Therapeutic Strategy for Myeloma Bone Disease. J.Bone Miner.Res. 2016; 31:1225-1234. This paper presents data on the effects of anti-scleorstin therapy in combination with carfilzomib in an animal model of early myeloma.

27. Balemans W, Ebeling M, Patel N, Van Hul E, Olson P, Dioszegi M, Lacza C, Wuyts W, Van Den Ende J, Willems P, Paes-Alves AF, Hill S, Bueno M, Ramos FJ, Tacconi P, Dikkers FG, Stratakis C, Lindpaintner $\mathrm{K}$, Vickery B, Foernzler D, Van Hul W. Increased bone density in sclerosteosis is due to the deficiency of a novel secreted protein (SOST). Hum.Mol.Genet. 2001; 10:537-543.

28. Balemans W, Van Den Ende J, Freire Paes-Alves A, Dikkers FG, Willems PJ, Vanhoenacker F, de Almeida-Melo N, Alves CF, Stratakis CA, Hill SC, Van Hul W. Localization of the gene for sclerosteosis to the van Buchem disease-gene region on chromosome 17q12-q21. Am.J.Hum.Genet. 1999; 64:16611669.

29. Baron R, Kneissel M. WNT signaling in bone homeostasis and disease: from human mutations to treatments. Nat.Med. 2013; 19:179-192.

30. Niziolek PJ, MacDonald BT, Kedlaya R, Zhang M, Bellido T, He X, Warman ML, Robling AG. High Bone Mass-Causing Mutant LRP5 Receptors Are Resistant to Endogenous Inhibitors In Vivo. J.Bone Miner.Res. 2015; 30:1822-1830. 
31. Delgado-Calle J, Sato AY, Bellido T. Role and mechanism of action of sclerostin in bone. Bone 2017; 96:29-37.

32. Li X, Ominsky MS, Niu QT, Sun N, Daugherty B, D'Agostin D, Kurahara C, Gao Y, Cao J, Gong J, Asuncion F, Barrero M, Warmington K, Dwyer D, Stolina M, Morony S, Sarosi I, Kostenuik PJ, Lacey DL, Simonet WS, Ke HZ, Paszty C. Targeted deletion of the sclerostin gene in mice results in increased bone formation and bone strength. J.Bone Miner.Res. 2008; 23:860-869.

33. Winkler DG, Sutherland MK, Geoghegan JC, Yu C, Hayes T, Skonier JE, Shpektor D, Jonas M, Kovacevich BR, Staehling-Hampton K, Appleby M, Brunkow ME, Latham JA. Osteocyte control of bone formation via sclerostin, a novel BMP antagonist. EMBO J. 2003; 22:6267-6276.

34. Loots GG, Kneissel M, Keller H, Baptist M, Chang J, Collette NM, Ovcharenko D, Plajzer-Frick I, Rubin EM. Genomic deletion of a long-range bone enhancer misregulates sclerostin in Van Buchem disease. Genome Res. 2005; 15:928-935.

35. Rhee Y, Allen MR, Condon K, Lezcano V, Ronda AC, Galli C, Olivos N, Passeri G, O'Brien CA, Bivi N, Plotkin LI, Bellido T. PTH receptor signaling in osteocytes governs periosteal bone formation and intracortical remodeling. J.Bone Miner.Res. 2011; 26:1035-1046.

36. Li X, Zhang Y, Kang H, Liu W, Liu P, Zhang J, Harris SE, Wu D. Sclerostin binds to LRP5/6 and antagonizes canonical Wnt signaling. J.Biol.Chem. 2005; 280:19883-19887.

37. Leupin O, Piters E, Halleux C, Hu S, Kramer I, Morvan F, Bouwmeester T, Schirle M, Bueno-Lozano M, Fuentes FJ, Itin PH, Boudin E, de FF, Jennes K, Brannetti B, Charara N, Ebersbach H, Geisse S, Lu CX, Bauer A, Van HW, Kneissel M. Bone overgrowth-associated mutations in the LRP4 gene impair sclerostin facilitator function. J.Biol.Chem. 2011; 286:19489-19500.

38. Stolina M, Dwyer D, Niu QT, Villasenor KS, Kurimoto P, Grisanti M, Han CY, Liu M, Li X, Ominsky MS, Ke HZ, Kostenuik PJ. Temporal changes in systemic and local expression of bone turnover markers during six months of sclerostin antibody administration to ovariectomized rats. Bone 2014; 67:305-313.

39. Glass DA, Bialek P, Ahn JD, Starbuck M, Patel MS, Clevers H, Taketo MM, Long F, McMahon AP, Lang RA, Karsenty G. Canonical Wnt signaling in differentiated osteoblasts controls osteoclast differentiation. Dev.Cell 2005; 8:751-764.

40. Holmen SL, Zylstra CR, Mukherjee A, Sigler RE, Faugere MC, Bouxsein ML, Deng L, Clemens TL, Williams BO. Essential role of beta-catenin in postnatal bone acquisition. J.Biol.Chem. 2005; 280:2116221168.

41. Kramer I, Halleux C, Keller H, Pegurri M, Gooi JH, Weber PB, Feng JQ, Bonewald LF, Kneissel M. Osteocyte Wnt/beta-catenin signaling is required for normal bone homeostasis. Mol.Cell Biol. 2010; 30:3071-3085.

42. Tu X, Delgado-Calle J, Condon KW, Maycas M, Zhang H, Carlesso N, Taketo MM, Burr DB, Plotkin LI, Bellido T. Osteocytes mediate the anabolic actions of canonical Wnt $/ \beta$-catenin signaling in bone. Proc.Natl.Acad.Sci U.S.A. 2015; 112:E478-E486.

43. Wijenayaka AR, Kogawa M, Lim HP, Bonewald LF, Findlay DM, Atkins GJ. Sclerostin stimulates osteocyte support of osteoclast activity by a RANKL-dependent pathway. PLoS.ONE. 2011; 6:e25900.

44. Amrein K, Amrein S, Drexler C, Dimai HP, Dobnig H, Pfeifer K, Tomaschitz A, Pieber TR, FahrleitnerPammer A. Sclerostin and its association with physical activity, age, gender, body composition, and bone mineral content in healthy adults. J.Clin.Endocrinol.Metab 2012; 97:148-154. 
45. Urano T, Shiraki M, Ouchi Y, Inoue S. Association of circulating sclerostin levels with fat mass and metabolic disease--related markers in Japanese postmenopausal women. J.Clin.Endocrinol.Metab 2012; 97:E1473-E1477.

46. Klangjareonchai T, Nimitphong H, Saetung S, Bhirommuang N, Samittarucksa R, Chanprasertyothin S, Sudatip R, Ongphiphadhanakul B. Circulating sclerostin and irisin are related and interact with gender to influence adiposity in adults with prediabetes. Int.J.Endocrinol. 2014; 2014:261545.

47. Ukita M, Yamaguchi T, Ohata N, Tamura M. Sclerostin Enhances Adipocyte Differentiation in 3T3-L1 Cells. J.Cell Biochem. 2016; 117:1419-1428.

48. Fairfield H, Falank C, Harris E, DeMambro V, McDonald M, Pettit JA, Mohanty ST, Croucher P, Kramer I, Kneissel M, Rosen CJ, Reagan MR. The Skeletal Cell-Derived Molecule Sclerostin Drives Bone Marrow Adipogenesis. J.Cell Physiol 2017; doi: 10.1002/jcp.25976.

49. Fulzele K, Lai F, Dedic C, Saini V, Uda Y, Shi C, Tuck P, Aronson JL, Liu X, Spatz JM, Wein M, Pajevic PD. Osteocyte-Secreted Wnt Signaling Inhibitor Sclerostin Contributes to Beige Adipogenesis in Peripheral Fat Depots. J.Bone Miner.Res. 2017; 32:373-384.

50. Kim SW, Lu Y, Williams EA, Lai F, Lee JY, Enishi T, Balani DH, Ominsky MS, Ke HZ, Kronenberg HM, Wein MN. Sclerostin Antibody Administration Converts Bone Lining Cells into Active Osteoblasts. J.Bone Miner.Res. 2016; 32:892-901.

51. Poole KE, Van Bezooijen RL, Loveridge N, Hamersma H, Papapoulos SE, Lowik CW, Reeve J. Sclerostin is a delayed secreted product of osteocytes that inhibits bone formation. FASEB J. 2005; 19:1842-1844.

52. Xiong J, Piemontese M, Onal M, Campbell J, Goellner JJ, Dusevich V, Bonewald L, Manolagas SC, O'Brien CA. Osteocytes, not Osteoblasts or Lining Cells, are the Main Source of the RANKL Required for Osteoclast Formation in Remodeling Bone. PLoS.ONE. 2015; 10:e0138189.

53. Pederson L, Ruan M, Westendorf JJ, Khosla S, Oursler MJ. Regulation of bone formation by osteoclasts involves Wnt/BMP signaling and the chemokine sphingosine-1-phosphate. Proc.Natl.Acad.Sci.U.S.A 2008; 105:20764-20769.

54. Ota K, Quint P, Ruan M, Pederson L, Westendorf JJ, Khosla S, Oursler MJ. Sclerostin is expressed in osteoclasts from aged mice and reduces osteoclast-mediated stimulation of mineralization. J.Cell Biochem. 2013; 114:1901-1907.

55. Jager A, Gotz W, Lossdorfer S, Rath-Deschner B. Localization of SOST/sclerostin in cementocytes in vivo and in mineralizing periodontal ligament cells in vitro. J.Periodontal Res. 2010; 45:246-254.

56. Van Bezooijen RL, Bronckers AL, Gortzak RA, Hogendoorn PC, Van der Wee-Pals L, Balemans W, Oostenbroek HJ, Van Hul W, Hamersma H, Dikkers FG, Hamdy NA, Papapoulos SE, Lowik CW. Sclerostin in mineralized matrices and van Buchem disease. J.Dent.Res. 2009; 88:569-574.

57. Roudier M, Li X, Niu QT, Pacheco E, Pretorius JK, Graham K, Yoon BR, Gong J, Warmington K, Ke HZ, Black RA, Hulme J, Babij P. Sclerostin is expressed in articular cartilage but loss or inhibition does not affect cartilage remodeling during aging or following mechanical injury. Arthritis Rheum. 2013; 65:721731.

58. Brandenburg VM, Kramann R, Koos R, Kruger T, Schurgers L, Muhlenbruch G, Hubner S, Gladziwa U, Drechsler C, Ketteler M. Relationship between sclerostin and cardiovascular calcification in hemodialysis patients: a cross-sectional study. BMC.Nephrol. 2013; 14:219. 
59. Shao JS, Cheng SL, Pingsterhaus JM, Charlton-Kachigian N, Loewy AP, Towler DA. Msx2 promotes cardiovascular calcification by activating paracrine Wnt signals. J.Clin.Invest 2005; 115:1210-1220.

60. Zhu D, Mackenzie NC, Millan JL, Farquharson C, MacRae VE. The appearance and modulation of osteocyte marker expression during calcification of vascular smooth muscle cells. PLoS.ONE. 2011; 6:e19595.

61. Wehmeyer C, Frank S, Beckmann D, Bottcher M, Cromme C, Konig U, Fennen M, Held A, Paruzel P, Hartmann C, Stratis A, Korb-Pap A, Kamradt T, Kramer I, van den Berg W, Kneissel M, Pap T, Dankbar B. Sclerostin inhibition promotes TNF-dependent inflammatory joint destruction. Sci.Transl.Med. 2016; 8:330ra35.

62. Colucci S, Brunetti G, Oranger A, Mori G, Sardone F, Specchia G, Rinaldi E, Curci P, Liso V, Passeri G, Zallone A, Rizzi R, Grano M. Myeloma cells suppress osteoblasts through sclerostin secretion. Blood Cancer J. 2011; 1:e27.

63. Brunetti G, Oranger A, Mori G, Specchia G, Rinaldi E, Curci P, Zallone A, Rizzi R, Grano M, Colucci S. Sclerostin is overexpressed by plasma cells from multiple myeloma patients. Ann.N.Y.Acad.Sci. 2011; 1237:19-23.

64. Staehling-Hampton K, Proll S, Paeper BW, Zhao L, Charmley P, Brown A, Gardner JC, Galas D, Schatzman RC, Beighton P, Papapoulos S, Hamersma H, Brunkow ME. A 52-kb deletion in the SOSTMEOX1 intergenic region on 17q12-q21 is associated with van Buchem disease in the Dutch population. Am.J.Med.Genet. 2002; 110:144-152.

65. Leupin O, Kramer I, Collette NM, Loots GG, Natt F, Kneissel M, Keller H. Control of the SOST bone enhancer by PTH using MEF2 transcription factors. J.Bone Miner.Res. 2007; 22:1957-1967.

66. Collette NM, Genetos DC, Economides AN, Xie L, Shahnazari M, Yao W, Lane NE, Harland RM, Loots GG. Targeted deletion of Sost distal enhancer increases bone formation and bone mass. Proc.Natl.Acad.Sci.U.S.A 2012; 109:14092-14097.

67. del Real A, Riancho JA, Delgado-Calle J. Epigenetic regulation of Sost/sclerostin expression. Current Molecular Biology Reports 2017; 3:85.

68. Delgado-Calle J, Sanudo C, Bolado A, Fernandez AF, Arozamena J, Pascual-Carra MA, Rodriguez-Rey JC, Fraga MF, Bonewald L, Riancho JA. DNA methylation contributes to the regulation of sclerostin expression in human osteocytes. J.Bone Miner.Res. 2012; 27:926-937.

69. Bellido T, Ali AA, Gubrij I, Plotkin LI, Fu Q, O'Brien CA, Manolagas SC, Jilka RL. Chronic elevation of PTH in mice reduces expression of sclerostin by osteocytes: a novel mechanism for hormonal control of osteoblastogenesis. Endocrinology 2005; 146:4577-4583.

70. Bellido T, Saini.V, Divieti Pajevic P. Effects of PTH on osteocyte function. Bone 2013; 54:250-257.

71. Keller H, Kneissel M. SOST is a target gene for PTH in bone. Bone 2005; 37:148-158.

72. Loots GG, Keller H, Leupin O, Murugesh D, Collette NM, Genetos DC. TGF-beta regulates sclerostin expression via the ECR5 enhancer. Bone 2012; 50:663-669.

73. Kamiya N, Ye L, Kobayashi T, Mochida Y, Yamauchi M, Kronenberg HM, Feng JQ, Mishina Y. BMP signaling negatively regulates bone mass through sclerostin by inhibiting the canonical Wnt pathway. Development 2008; 135:3801-3811. 
74. Delgado-Calle J, Arozamena J, Perez-Lopez J, Bolado-Carrancio A, Sanudo C, Agudo G, de l, V, Alonso MA, Rodriguez-Rey JC, Riancho JA. Role of BMPs in the regulation of sclerostin as revealed by an epigenetic modifier of human bone cells. Mol.Cell Endocrinol. 2013; 369:27-34.

75. Vincent C, Findlay DM, Welldon KJ, Wijenayaka AR, Zheng TS, Haynes DR, Fazzalari NL, Evdokiou A, Atkins GJ. Pro-inflammatory cytokines TNF-related weak inducer of apoptosis (TWEAK) and TNFalpha induce the mitogen-activated protein kinase (MAPK)-dependent expression of sclerostin in human osteoblasts. J Bone Miner Res 2009; 24:1434-1449.

76. Koide M, Kobayashi Y, Yamashita T, Uehara S, Nakamura M, Hiraoka BY, Ozaki Y, Iimura T, Yasuda H, Takahashi N, Udagawa N. Bone formation is coupled to resorption via suppression of sclerostin expression by osteoclasts. J.Bone Miner.Res. 2017; doi: 10.1002/jbmr.3175.

77. Delgado-Calle J. Osteocytes and their messengers as targets for the treament of multiple myeloma. Clinical Reviews in Bone and Mineral Metabolism 2017; 15:49-56.

78. Giuliani N, Ferretti M, Bolzoni M, Storti P, Lazzaretti M, Dalla PB, Bonomini S, Martella E, Agnelli L, Neri A, Ceccarelli F, Palumbo C. Increased osteocyte death in multiple myeloma patients: role in myeloma-induced osteoclast formation. Leukemia 2012; 26:1391-1401.

79. •Delgado-Calle J, Anderson J, Cregor MD, Hiasa M, Chirgwin JM, Carlesso N, Yoneda T, Mohammad KS, Plotkin LI, Roodman GD, Bellido T. Bidirectional Notch signaling and osteocyte-derived factors in the bone marrow microenvironment promote tumor cell proliferation and bone destruction in multiple myeloma. Cancer Res. 2016; 76:1089-1100. This paper desribes for the first time overproduciton of sclerostin by osteocytes in bones colonized by myeloma cells.

80. Toscani D, Palumbo C, Dalla PB, Ferretti M, Bolzoni M, Marchica V, Sena P, Martella E, Mancini C, Ferri V, Costa F, Accardi F, Craviotto L, Aversa F, Giuliani N. The Proteasome Inhibitor Bortezomib Maintains Osteocyte Viability in Multiple Myeloma Patients by Reducing Both Apoptosis and Autophagy: A New Function for Proteasome Inhibitors. J.Bone Miner.Res. 2016; 31:815-827.

81. Hiasa M, Okui T, Allette YM, Ripsch MS, Sun-Wada GH, Wakabayashi H, Roodman GD, White FA, Yoneda T. Bone Pain Induced by Multiple Myeloma Is Reduced by Targeting V-ATPase and ASIC3. Cancer Res. 2017; 77:1283-1295.

82. Sottnik JL, Campbell B, Mehra R, Behbahani-Nejad O, Hall CL, Keller ET. Osteocytes serve as a progenitor cell of osteosarcoma. J.Cell Biochem. 2014; 115:1420-1429.

83. Inagaki Y, Hookway ES, Kashima TG, Munemoto M, Tanaka Y, Hassan AB, Oppermann U, Athanasou NA. Sclerostin expression in bone tumours and tumour-like lesions. Histopathology 2016; 69:470-478.

84. Mendoza-Villanueva D, Zeef L, Shore P. Metastatic breast cancer cells inhibit osteoblast differentiation through the Runx2/CBFbeta-dependent expression of the Wnt antagonist, sclerostin. Breast Cancer Res. 2011; 13:R106.

85. Wibmer C, Amrein K, Fahrleitner-Pammer A, Gilg MM, Berghold A, Hutterer GC, Maurer-Ertl W, Gerger A, Leithner A, Pichler M, Szkandera J. Serum sclerostin levels in renal cell carcinoma patients with bone metastases. Sci.Rep. 2016; 6:33551.

86. Rossini M, Viapiana O, Zanotti R, Tripi G, Perbellini O, Idolazzi L, Bonifacio M, Adami S, Gatti D. Dickkopf-1 and sclerostin serum levels in patients with systemic mastocytosis. Calcif.Tissue Int. 2015; 96:410-416. 
87. Roforth MM, Fujita K, McGregor UI, Kirmani S, McCready LK, Peterson JM, Drake MT, Monroe DG, Khosla S. Effects of age on bone mRNA levels of sclerostin and other genes relevant to bone metabolism in humans. Bone 2014; 59:1-6.

88. Modder UI, Hoey KA, Amin S, McCready LK, Achenbach SJ, Riggs BL, Melton LJ, III, Khosla S. Relation of age, gender, and bone mass to circulating sclerostin levels in women and men. J.Bone Miner.Res. 2010; 26:373-379.

89. Hudson BD, Hum NR, Thomas CB, Kohlgruber A, Sebastian A, Collette NM, Coleman MA, Christiansen BA, Loots GG. SOST Inhibits Prostate Cancer Invasion. PLoS.One. 2015; 10:e0142058.

90. Sebastian A, Hum NR, Hudson BD, Loots GG. Cancer-Osteoblast Interaction Reduces Sost Expression in Osteoblasts and Up-Regulates lncRNA MALAT1 in Prostate Cancer. Microarrays.(Basel) 2015; 4:503-519.

91. Wang XT, He YC, Zhou SY, Jiang JZ, Huang YM, Liang YZ, Lai YR. Bone marrow plasma macrophage inflammatory protein protein-1 alpha(MIP-1 alpha) and sclerostin in multiple myeloma: relationship with bone disease and clinical characteristics. Leuk.Res. 2014; 38:525-531.

92. $\bullet$ McDonald MM, Reagan MR, Youlten SE, Mohanty ST, Seckinger A, Terry RL, Pettitt JA, Simic MK, Cheng TL, Morse A, Le LMT, Abi-Hanna D, Kramer I, Falank C, Fairfield H, Ghobrial IM, Baldock PA, Little DG, Kneissel M, Vanderkerken K, Bassett JHD, Williams GR, Oyajobi BO, Hose D, Phan TG, Croucher PI. Inhibiting the osteocyte specific protein sclerostin increases bone mass and fracture resistance in multiple myeloma. Blood 2017; doi: 10.1182/blood-2017-03-773341. This study demonstrates the efficay of anti-sclerostin therapy, alone and in combinaiton with a bisphosphonate, to prevent bone loss and improve bone mechanical properties in mouse and human xenograft models of myeloma.

93. • •Delgado-Calle J, Anderson J, Cregor MD, Condon KW, Kuhstoss SA, Plotkin LI, Bellido T, Roodman GD. Genetic deletion of sost or pharmacological inhibition of sclerostin prevent multiple myeloma-induced bone disease without affecting tumor growth. Leukemia 2017; doi: 10.1038/leu.2017.152. This study shows that genetic and pharmacologic inhibition of Sost/sclerostin prevents bone loss and stimulates bone formation in a mouse model of established myeloma.

94. Coleman R, Gnant M, Morgan G, Clezardin P. Effects of bone-targeted agents on cancer progression and mortality. J.Natl.Cancer Inst. 2012; 104:1059-1067.

95. Ominsky MS, Boyce RW, Li X, Ke HZ. Effects of sclerostin antibodies in animal models of osteoporosis. Bone 2017; 96:63-75.

96. McClung MR. Clinical utility of anti-sclerostin antibodies. Bone 2017; 96:3-7.

97. McClung MR, Grauer A, Boonen S, Bolognese MA, Brown JP, ez-Perez A, Langdahl BL, Reginster JY, Zanchetta JR, Wasserman SM, Katz L, Maddox J, Yang YC, Libanati C, Bone HG. Romosozumab in Postmenopausal Women with Low Bone Mineral Density. N.Engl.J.Med. 2014; 370:412-420.

98. Keaveny TM, Crittenden DB, Bolognese MA, Genant HK, Engelke K, Oliveri B, Brown JP, Langdahl BL, Yan C, Grauer A, Libanati C. Greater Gains in Spine and Hip Strength for Romosozumab Compared to Teriparatide in Postmenopausal Women With Low Bone Mass. J.Bone Miner.Res. 2017; doi: 10.1002/jbmr.3176.

99. Zhan T, Rindtorff N, Boutros M. Wnt signaling in cancer. Oncogene 2017; 36:1461-1473.

100. Derksen PW, Tjin E, Meijer HP, Klok MD, MacGillavry HD, van Oers MH, Lokhorst HM, Bloem AC, Clevers H, Nusse R, van der Neut R, Spaargaren M, Pals ST. Illegitimate WNT signaling promotes proliferation of multiple myeloma cells. Proc.Natl.Acad.Sci.U.S.A 2004; 101:6122-6127. 
101. Gregory LS, Choi W, Burke L, Clements JA. Breast cancer cells induce osteolytic bone lesions in vivo through a reduction in osteoblast activity in mice. PLoS.ONE. 2013; 8:e68103.

102. Bu G, Lu W, Liu CC, Selander K, Yoneda T, Hall C, Keller ET, Li Y. Breast cancer-derived Dickkopf1 inhibits osteoblast differentiation and osteoprotegerin expression: implication for breast cancer osteolytic bone metastases. Int.J.Cancer 2008; 123:1034-1042.

103. Voorzanger-Rousselot N, Goehrig D, Journe F, Doriath V, Body JJ, Clezardin P, Garnero P. Increased Dickkopf-1 expression in breast cancer bone metastases. Br.J.Cancer 2007; 97:964-970.

104. Kristensen IB, Christensen JH, Lyng MB, Moller MB, Pedersen L, Rasmussen LM, Ditzel HJ, Abildgaard $\mathrm{N}$. Expression of osteoblast and osteoclast regulatory genes in the bone marrow microenvironment in multiple myeloma: only up-regulation of Wnt inhibitors SFRP3 and DKK1 is associated with lytic bone disease. Leuk.Lymphoma 2013; 55:911-919.

105. Heath DJ, Chantry AD, Buckle CH, Coulton L, Shaughnessy JD, Jr., Evans HR, Snowden JA, Stover DR, Vanderkerken K, Croucher PI. Inhibiting Dickkopf-1 (Dkk1) removes suppression of bone formation and prevents the development of osteolytic bone disease in multiple myeloma. J.Bone Miner.Res. 2009; 24:425-436.

106. Yaccoby S, Ling W, Zhan F, Walker R, Barlogie B, Shaughnessy JD, Jr. Antibody-based inhibition of DKK1 suppresses tumor-induced bone resorption and multiple myeloma growth in vivo. Blood 2007; 109:2106-2111.

107. Fulciniti M, Tassone P, Hideshima T, Vallet S, Nanjappa P, Ettenberg SA, Shen Z, Patel N, Tai YT, Chauhan D, Mitsiades C, Prabhala R, Raje N, Anderson KC, Stover DR, Munshi NC. Anti-DKK1 mAb (BHQ880) as a potential therapeutic agent for multiple myeloma. Blood 2009; 114:371-379.

108. Florio M, Gunasekaran K, Stolina M, Li X, Liu L, Tipton B, Salimi-Moosavi H, Asuncion FJ, Li C, Sun B, Tan HL, Zhang L, Han CY, Case R, Duguay AN, Grisanti M, Stevens J, Pretorius JK, Pacheco E, Jones H, Chen Q, Soriano BD, Wen J, Heron B, Jacobsen FW, Brisan E, Richards WG, Ke HZ, Ominsky MS. A bispecific antibody targeting sclerostin and DKK-1 promotes bone mass accrual and fracture repair. Nat.Commun. 2016; 7:11505.

109. McDonald MM, Morse A, Mikulec K, Peacock L, Yu N, Baldock PA, Birke O, Liu M, Ke HZ, Little DG. Inhibition of sclerostin by systemic treatment with sclerostin antibody enhances healing of proximal tibial defects in ovariectomized rats. J.Orthop.Res. 2012; 30:1541-1548.

110. Suen PK, He YX, Chow DH, Huang L, Li C, Ke HZ, Ominsky MS, Qin L. Sclerostin monoclonal antibody enhanced bone fracture healing in an open osteotomy model in rats. J.Orthop.Res. 2014; 32:997-1005.

111. Liu Y, Rui Y, Cheng TY, Huang S, Xu L, Meng F, Lee WY, Zhang T, Li N, Li C, Ke H, Li G. Effects of Sclerostin Antibody on the Healing of Femoral Fractures in Ovariectomised Rats. Calcif.Tissue Int. 2016; 98:263-274.

112. Feng G, Chang-Qing Z, Yi-Min C, Xiao-Lin L. Systemic administration of sclerostin monoclonal antibody accelerates fracture healing in the femoral osteotomy model of young rats. Int.Immunopharmacol. 2015; 24:7-13.

113. Morse A, McDonald MM, Schindeler A, Peacock L, Mikulec K, Cheng TL, Liu M, Ke HZ, Little DG. Sclerostin Antibody Increases Callus Size and Strength but does not Improve Fracture Union in a Challenged Open Rat Fracture Model. Calcif.Tissue Int. 2017; doi: 10.1007/s00223-017-0275-2. 
114. Tinsley BA, Dukas A, Pensak MJ, Adams DJ, Tang AH, Ominsky MS, Ke HZ, Lieberman JR. Systemic Administration of Sclerostin Antibody Enhances Bone Morphogenetic Protein-Induced Femoral Defect Repair in a Rat Model. J.Bone Joint Surg.Am. 2015; 97:1852-1859.

115. Trotter TN, Gibson JT, Sherpa TL, Gowda PS, Peker D, Yang Y. Adipocyte-Lineage Cells Support Growth and Dissemination of Multiple Myeloma in Bone. Am.J.Pathol. 2016; 186:3054-3063.

116. Yu W, Cao DD, Li QB, Mei HL, Hu Y, Guo T. Adipocytes secreted leptin is a pro-tumor factor for survival of multiple myeloma under chemotherapy. Oncotarget. 2016; 7:86075-86086.

117. Morris EV, Edwards CM. Bone Marrow Adipose Tissue: A New Player in Cancer Metastasis to Bone. Front Endocrinol.(Lausanne) 2016; 7:90.

118. Fowler JA, Lwin ST, Drake MT, Edwards JR, Kyle RA, Mundy GR, Edwards CM. Host-derived adiponectin is tumor-suppressive and a novel therapeutic target for multiple myeloma and the associated bone disease. Blood 2011; 118:5872-5882. 